\title{
Control of salt and volume retention cannot be ruled out as a mechanism underlying the blood pressure-lowering effect of renal denervation
}

\author{
Hypertension Research (2013) 36, 1006-1007; doi:10.1038/hr.2013.82; published online 15 August 2013
}

Catheter-based renal denervation (RDN) has been increasingly used to lower blood pressure (BP) in patients with treatmentresistant hypertension. However, the underlying mechanisms by which RDN is effective are not well understood.

In Hypertension Research, Kimura published a commentary' ${ }^{1}$ titled 'Future of catheter-based renal denervation: key issues to solve', which identified some key issues for future research on $\mathrm{RDN}$. The author correctly pointed out that there exist salt- and volume-independent mechanisms underlying the BP-lowing effect of RDN, for example, a decrease in renal vascular resistance, a decrease in renin-angiotensin system activity and a decrease in afferent nerve activity. ${ }^{2}$ However, Kimura ${ }^{1}$ suggested that control of salt and volume retention is not the mechanism by which RDN lowers BP, based on what we consider two inappropriate pieces of evidence:

(1) The author stated that 'RDN effectively lowered BP in a hypertensive model with non-salt sensitive hypertension, such as SHR (spontaneously hypertensive rats). In contrast, RDN could not lower BP in saltsensitive models, including DOCA-salt (deoxycorticosterone acetate) hypertension and $1 \mathrm{~K}-1 \mathrm{C}$ (one-kidney, one-clip) Goldblatt hypertensive models. ${ }^{3}$ ' However, the cited reference ${ }^{3}$ stated that RDN can lower BP in all three models of hypertension mentioned above. The effectiveness of RDN in lowering $\mathrm{BP}$ in these three models of hypertension is supported by other reports using $\mathrm{SHR},{ }^{4}$ DOCA-salt ${ }^{5}$ and $1 \mathrm{~K}-1 \mathrm{C}^{6}$ models of hypertension. These results suggest that RDN can lower BP independent of the status of salt sensitivity.
(2) Kimura ${ }^{1}$ stated that 'three cases ${ }^{7-9}$ were described whose BP was successfully lowered without reducing dry weight or body fluid volume in hemodialysis patients with no residual renal function to excrete urine.' However, these patients with end-stage renal disease in those studies mentioned above still had residual renal function, ${ }^{7,8}$ and $\mathrm{RDN}$ did not worsen the residual renal function during the study period. In addition, these three case reports using three individual patients complicated with end-stage renal disease were unable to address the importance of salt and volume retention in mediating the effect of RDN. Moreover, the majority of patients who have been treated with RDN were not complicated with end-stage renal disease. Thus, these studies did not rule out the importance of control of salt and volume retention in mediating the effect of RDN.

Different from Kimura's opinion, evidence suggests that control of salt and volume retention may be one of the mechanisms underlying BP-lowering effect of RDN.

For example, RDN lowered $\mathrm{BP}$ in both $\mathrm{SHR}^{4}$ and DOCA salt-induced hypertensive rats, ${ }^{5}$ which was accompanied by an increase in sodium excretion ${ }^{5}$ and a decrease in cumulative sodium and water balances, suggesting that efferent control of sodium and water balance contributes to BP-lowering effect of RDN in these models of hypertension.

In humans, RDN decreases BP which was accompanied by a decrease in noradrenaline spillover, a decrease in plasma renin activity and an increase in renal blood flow. ${ }^{10}$ These findings suggest that control of salt and volume retention may be one of the mechanisms underlying the BP-lowering effect of RDN in humans. However, well-designed studies are needed to clarify this issue.

The importance of this mechanism varies in different models of hypertension. For example, in the $1 \mathrm{~K}-1 \mathrm{C}$ model of renovascular hypertension, RDN decreased BP but did not alter renal sodium excretion, ${ }^{6}$ suggesting that other mechanisms are responsible for the antihypertensive effect of RDN in renovascular hypertension. These mechanisms may include a decrease in plasma noradrenaline, a decrease in peripheral sympathetic nervous system activity and a decrease in the afferent renal nerve activity.

In summary, RDN lowers $\mathrm{BP}$ via multiple mechanisms, and control of salt and volume retention may be one of them.

\section{CONFLICT OF INTEREST}

The authors declare no conflict of interest.

\section{ACKNOWLEDGEMENTS}

This work was funded by grants from the National Health and Medical Research Council (540404, 1021416) and the BUPA Foundation. JG holds a Practitioner Fellowship from the National Health and Medical Research Council, Australia (1019921) and a Senior Clinical Research Fellowship from the Queensland Government.

Yutang Wang ${ }^{1}$, Kate M Denton ${ }^{2}$ and Jonathan Golledge ${ }^{1}$

${ }^{1}$ The Vascular Biology Unit, Queensland Research Centre for Peripheral

Vascular Disease, School of Medicine and Dentistry, James Cook University, Townsville, Queensland, Australia and ${ }^{2}$ Cardiovascular and Renal Physiology,

Department of Physiology, Monash

University, Clayton, Victoria, Australia E-mail: jonathan.golledge@jcu.edu.au 
1 Kimura G. Future of catheter-based renal denervation: key issues to solve. Hypertens Res 2013; 36 492-493.

2 Wang Y, Seto SW, Golledge J. Therapeutic effects of renal denervation on renal failure. Curr Neurovasc Res 2013; 10: 172-184.

3 DiBona GF. Physiology in perspective: the Wisdom of the Body. Neural control of the kidney. Am J Physiol Regul Integr Comp Physiol 2005; 289: R633-R641.

4 Winternitz SR, Katholi RE, Oparil S. Role of the renal sympathetic nerves in the development and maintenance of hypertension in the spontaneously hypertensive rat. J Clin Invest 1980; 66: 971-978.
5 Katholi RE, Naftilan AJ, Oparil S. Importance of renal sympathetic tone in the development of DOCA-salt hypertension in the rat. Hypertension 1980; 2: 266-273.

6 Katholi RE, Winternitz SR, Oparil S. Role of the renal nerves in the pathogenesis of one-kidney renal hypertension in the rat. Hypertension 1981; 3 : 404-409.

7 Prochnau D, Lauten A, Busch M, Kuehnert H, Figulla HR, Surber R. Catheter-based radiofrequency ablation therapy of the renal sympathetic-nerve system for drug resistant hypertension in a patient with end-stage renal disease. Int J Cardiol 2012; 154: e29-e30.
8 Di Daniele N, De Francesco M, Violo L, Spinelli A, Simonetti G. Renal sympathetic nerve ablation for the treatment of difficult-to-control or refractory hypertension in a haemodialysis patient. Nephrol Dial Transplant 2012; 27: 1689-1690.

9 Ott C, Schmid A, Ditting T, Sobotka PA, Veelken R, Uder M, Schmieder RE. Renal denervation in a hypertensive patient with end-stage renal disease and small arteries: a direction for future research. J Clin Hypertens (Greenwich) 2012; 14: 799-801.

10 Schlaich MP, Sobotka PA, Krum H, Lambert E, Esler MD. Renal sympathetic-nerve ablation for uncontrolled hypertension. N Engl J Med 2009; 361: 932-934. 